\title{
SARS-CoV-2 impact in a community-based hematological ward in an Italian Red Zone
}

\author{
Giuseppe Visani $^{1} \cdot$ Martina Chiarucci $^{1} \cdot$ Barbara Guiducci $^{1} \cdot$ Maria Capalbo $^{1} \cdot$ Alessandro Isidori $^{1}$ (D)
}

Received: 4 May 2020 / Accepted: 1 June 2020 / Published online: 13 June 2020

(C) Springer-Verlag GmbH Germany, part of Springer Nature 2020

\section{Dear Editor,}

Covid-19 pandemia is posing a formidable threat worldwide [1]. Initial reports from China suggested that patients with cancer had an estimated two-fold increased risk of contracting SARS-CoV-2 than the general population and, if infected, also had a higher risk of either ICU admission, invasive ventilation, or death, compared to patients without cancer [2].

Patients with hematologic malignancies are generally immunocompromised due to the underlying malignancy or anticancer therapy and thus are at higher risk of developing infections [3]. Accordingly, hematological patients present a unique challenge during this pandemic.

In recent weeks, Covid-19 has rapidly spread throughout Italy. Daily confirmed SARS-CoV-2 positive cases in our area grew up until late March, to a positive rate of $41 \%$, starting, then, to progressively decrease. Up to now, 5924 cases resulted SARS-CoV-2 positive in Marche Region (out of 30,543 test done), with a rhythm of infection and death toll five times superior those of China [4]; 845 patients died (452 in Pesaro Area) due to Covid-19, with high case-fatality rate $(14 \%)$.

We faced the outbreak as follows. First, we restricted the Ward admission rules: personal protective equipment (surgical mask, disposable gown) was mandatory for all healthcare professionals (HCPs), with hands disinfection, distancing, and strict reduction of access to relatives. Protective clothing was changed at the beginning and

Giuseppe Visani

giuseppe.visani@ospedalimarchenord.it

Alessandro Isidori

alessandro.isidori@ospedalimarchenord.it

1 Hematology and Hematopoietic Stem Cell Transplant Center, AORMN Marche Nord, Pesaro, Italy end of the shift. Second, patient triage was performed by telephonic interviews, questioning on symptoms (fever, cough, rhinitis, diarrhea) during the 15 days before and contacts with positive subjects. Finally, we implemented testing with nasopharyngeal swabs and a quantitative polymerase-chain-reaction test to detect SARS-CoV-2 infection in patients admitted for chemotherapy/stem cell transplantation.

Between February 22nd and April 22nd, we tested 116 patients with hematological malignancies (age 1682 years), either at our department (70 patients: leukemia 21, lymphoma 27, myeloma 11, MDS 4, miscellaneous 7) or at the ER (46 patients, mainly AML or lymphoma). Nine patients (8\%, 5 lymphoma, 2 AML, 1 myeloma, 1 ITP) had fever or other Covid-19 symptoms. All of them resulted positive and were hospitalized; $4 / 9$ died due to interstitial pneumonia, 3 are still hospitalized, either in Covid-Unit or in ICU, and 2 were discharged in good medical conditions (1 ITP, 1 myeloma). Among asymptomatic patients, 5/116 (4\%) patients resulted Covid-19 positive. They were not admitted to the Ward and had a deferral in chemotherapy.

The remaining 101 patients who had a negative nasopharyngeal swab were admitted to the ward and received standard chemotherapy without delays. None of them resulted, at later tests, positive, or developed symptoms. No COVID-19 prophylaxis was administered at any time. Notably, 4 allogeneic and 8 autologous stem cell transplants were successfully performed during the outbreak.

Thirty-five HCPs, working exclusively at our Center, were tested: none of them resulted SARS-CoV-2 positive by nasopharyngeal swab. This is outstanding, as more than 17,000 HCPs resulted positive in Italy up to now according to the Italian Institute of Health (ISS).

Our experience demonstrates that protection measures, thoroughly applied and coupled with extensive testing, allow patients with hematologic malignancies to preserve their chance of cure even during SARS-CoV-2 pandemia. 
Acknowledgments We thank all the healthcare professionals (doctors, nurses, data managers) working at the Hematology and Transplant Center in Pesaro for their hard work during COVID-19 pandemic. We thank Dr. Maria Capalbo and the Board of Directors of AORMN for their support.

\section{Compliance with ethical standards}

Conflict of interest The authors declare that they have no conflict of interest.

Ethical approval All procedures performed in studies involving human participants were in accordance with the ethical standards of the institutional and/or national research committee and with the 1964 Helsinki Declaration and its later amendments or comparable ethical standards.

Informed consent Informed consent was obtained from all individual participants included in the study.

\section{References}

1. Zhu N, Zhang D, Wang W, Li X, Yang B, Song J, Zhao X, Huang B, Shi W, Lu R, Niu P, Zhan F, Ma X, Wang D, Xu W, Wu G, Gao GF, Tan W, China Novel Coronavirus Investigating and Research Team (2020) A novel coronavirus from patients with pneumonia in China, 2019. N Engl J Med 382:727-733

2. Liang W, Guan W, Chen R, Wang W, Li J, Xu K, Li C, Ai Q, Lu W, Liang H, Li S, He J (2020) Cancer patients in SARS-CoV-2 infection: a nationwide analysis in China. Lancet Oncol 21:335-337

3. Maschmeyer G, De Greef J, Mellinghoff SC et al (2019) Infections associated with immunotherapeutic and molecular targeted agents in hematology and oncology. A position paper by the European Conference on Infections in Leukemia (ECIL). Leukemia 33(4): 844-862

4. Guan W, Ni Z, Hu Y et al Clinical characteristics of coronavirus disease 2019 in China (2020). N Engl J Med. https://doi.org/10. 1056/NEJMoa2002032

Publisher's note Springer Nature remains neutral with regard to jurisdictional claims in published maps and institutional affiliations. 